\title{
Bermuda Grass Pollen IgG4 Measurement
}

National Cancer Institute

\section{Source}

National Cancer Institute. Bermuda Grass Pollen Ig G4 Measurement. NCI Thesaurus. Code C130071.

A measurement of the Bermuda grass (Cynodon dactylon) pollen IgG4 in a biological specimen. 